\title{
Correction to: Regulation of algal and cyanobacterial auxin production, physiology, and application in agriculture: an overview
}

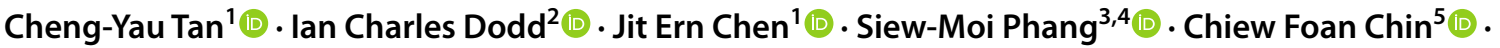 \\ Yoon-Yen Yow ${ }^{1}$ (i) . Shyamala Ratnayeke ${ }^{1}$ (I)
}

Published online: 16 July 2021

(c) Springer Nature B.V. 2021

\section{Correction to: J Appl Phycol \\ https://doi.org/10.1007/s10811-021-02475-3}

The original version of this article unfortunately contained a mistake. The spelling of the word "physiological" in the Abstract was misspelled as "phsiological". The original article has been corrected.

Publisher's note Springer Nature remains neutral with regard to jurisdictional claims in published maps and institutional affiliations.

The original article can be found online at https://doi.org/10.1007/ s10811-021-02475-3.

Shyamala Ratnayeke

shyamalar@sunway.edu.my

1 Department of Biological Sciences, School

of Medical and Life Sciences, Sunway University,

47500 Bandar Sunway, Selangor Darul Ehsan, Malaysia

2 The Lancaster Environment Centre, Lancaster University, Lancaster LA1 4YQ, UK

3 Institute of Ocean and Earth Sciences, University of Malaya, 50603 Kuala Lumpur, Malaysia

4 Faculty of Applied Sciences, UCSI University, Cheras, 56000 Kuala Lumpur, Malaysia

5 School of Biosciences, Faculty of Science and Engineering, University of Nottingham Malaysia Campus, Jalan Broga, 43500 Semenyih, Selangor Darul Ehsan, Malaysia 